\title{
EL ANÁLISIS LÓGICO DE LA PREDICACIÓN COLECTIVA
}

\author{
Gustavo Fernández DíEZ \\ Departamento de Filosofía \\ Universidad de Murcia \\ gfdezdp@um.es
}

RESUMEN: En el presente artículo se examinan algunos de los problemas suscitados por el análisis lógico de la predicación colectiva (aquella en la que un predicado se aplica colectivamente a una pluralidad de sujetos). Su tratamiento habitual en lógica de primer orden no es del todo satisfactorio, y la búsqueda de otros modos de representación abre interesantes perspectivas. Se investiga, en particular, la introducción de predicados poligraduados, señalando algunas deficiencias e insuficiencias en la literatura reciente sobre los mismos. Argumento que la oposición colectivo/distributivo debe localizarse en la estructura lógica del enunciado en cuestión.

PALABRAS CLAVE: colectivo/distributivo, predicado poligraduado, término compuesto, lógica plural

SUMMARY: In this paper I investigate the logical analysis of statements in which a predicate applies collectively to a plurality of subjects. The standard treatment of such cases in first-order logic is not completely satisfactory, and the search for alternative modes of representation opens up interesting perspectives. I concentrate on the introduction of multigrade predicates, pointing out a number of weaknesses in the current literature on the subject. I argue that the collective/distributive opposition must be located in the logical structure of the statement in question.

KEY WORDS: collective/distributive, multigrade predicate, compound term, plural logic

\section{Predicación colectiva y predicación distributiva}

La diferencia entre la verdad de los enunciados:

(1) "Isabel y Fernando rigieron los destinos de España"

$\mathrm{y}$

(2) "Carlos I y Felipe II rigieron los destinos de España"

es que Isabel y Fernando (los Reyes Católicos) gobernaron España conjuntamente, mientras que Carlos I y Felipe II lo hicieron en momentos distintos. En (1) tenemos, por tanto, una predicación colectiva, porque lo que se predica ("regir los destinos de España") sólo se puede aplicar a los dos sujetos de la predicación (Isabel y Fernando) tomados de forma conjunta. En cambio, en (2) tenemos una predicación distributiva, porque el mismo predicado ("regir los 
destinos de España") corresponde aquí a cada uno de los sujetos de la predicación (Carlos I y Felipe II) por separado.

Si ponemos:

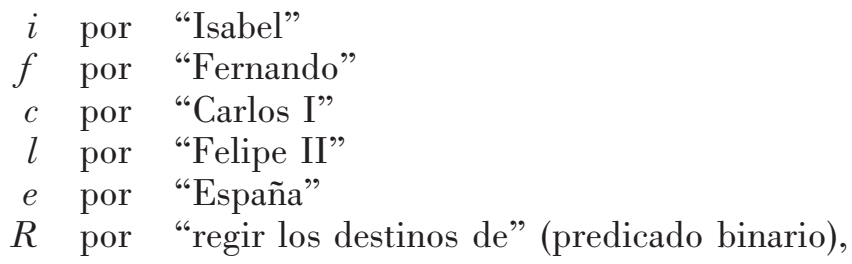

parece claro que podemos formalizar (2) mediante $R(c, e) \wedge R(l, e)$, mientras que para formalizar (1) no podemos admitir la conjunción análoga: $R(i, e) \wedge R(f, e)$. En efecto, tal conjunción implicaría que, en particular, Isabel la Católica rigió alguna vez los destinos de España ella sola, y eso no es cierto.

El presente artículo tiene dos objetivos principales. El primero es estudiar cómo se puede formalizar un enunciado de predicación colectiva como (1), para que su estructura lógica quede representada del modo más adecuado y transparente posible. A ello dedicaremos las secciones 2-11. El segundo objetivo es ahondar en la oposición entre predicación colectiva y predicación distributiva, que a pesar de sus diferencias, da lugar a enunciados superficialmente tan similares como (1) y (2). Este segundo objetivo será el tema de las secciones $12-16$.

\section{Objetos compuestos y conjuntos}

La distinción entre predicación colectiva y predicación distributiva es muy antigua, se remonta a Aristóteles (cfr. Sobre las refutaciones sofísticas IV, 166a, 15-35, y para un breve recorrido histórico, véase Lasersohn 1995, pp. 12-17). También fue formulada por Frege:

Cuando decimos "Schiller y Goethe son poetas", realmente no estamos conectando los nombres propios con "y", sino las oraciones "Schiller es un poeta" y "Goethe es un poeta", que han sido comprimidas en una. Es diferente la oración "Siemens y Halske han construido la primera gran red de telégrafos". Aquí no tenemos una forma comprimida de dos oraciones, sino que "Siemens y Halske" designa un objeto compuesto acerca del cual se hace un enunciado, y la palabra "y" se utiliza para contribuir a formar la expresión para ese objeto. (Frege 1914, pp. 227228) 
Siguiendo lo que sugiere Frege, podríamos tratar de formalizar (1) mediante la introducción de una nueva constante para denotar al "objeto compuesto" de Isabel y Fernando, esto es, al matrimonio reinante. Supongamos que así lo hacemos poniendo, por ejemplo, $m$ por "Isabel y Fernando" y, por tanto, formalizando el enunciado (1) mediante $R(m, e)$.

¿Es $R(m, e)$ una formalización adecuada de (1)? Parece que no, porque a partir de $R(m, e)$ resulta imposible, por ejemplo, justificar una inferencia como la que va de

(1) "Isabel y Fernando rigieron los destinos de España"

a:

(3) "Hubo alguien que, junto con Isabel, rigió los destinos de España"

Ahora bien, el paso de (1) a (3) es una inferencia lógica elemental, del tipo de las que esperamos que nuestras herramientas de análisis lógico sean capaces de dar cuenta. Por consiguiente, la introducción de una constante para denotar al "objeto compuesto" de Isabel y Fernando no nos proporciona una representación completamente satisfactoria de la estructura lógica de (1).

También podemos plantearnos el tratar a la pareja Isabel y Fernando como un conjunto, en el sentido de la moderna teoría de conjuntos; es decir, representar al matrimonio de Isabel y Fernando como el conjunto $\{i, f\}$. Ello nos permitiría derivar la inferencia de (1) a (3) mediante la utilización de un cálculo deductivo apropiado, el de Zermelo-Fraenkel, por ejemplo:

$$
R(\{i, f\}, e) \quad \vdash_{Z F} \quad \exists x R(\{i, x\}, e) .
$$

Sin embargo, parece exagerado apelar a una teoría de tanto calado matemático como la teoría de conjuntos (por sus implicaciones ontológicas y sus limitaciones metateóricas) para dar cuenta de una inferencia tan sencilla como la que va de (1) a (3). Es decir, aun admitiendo que la teoría de conjuntos de Zermelo-Fraenkel constituye una herramienta suficiente para representar formalmente la inferencia de (1) a (3), parece razonable preguntarse si no será posible dar cuenta de dicha inferencia mediante la utilización de alguna otra teoría más elemental.

Y, en particular, parece razonable preguntarse si no será posible representar la inferencia de (1) a (3) como una inferencia puramente 
lógica; esto es, mediante la simple utilización del cálculo de predicados de primer orden, tal cual.

El propio Frege, por cierto, desaconsejaba hablar de "clases" en este contexto:

"Bunsen y Kirchoff pusieron las bases del análisis espectral." Aquí debemos considerar Bunsen y Kirchoff como un todo [...] o sistema, compuesto por partes [...]. La clase de los números primos es un objeto, pero no un todo cuyas partes fueran números primos. [...] Ese caso difiere del anterior. (Frege 1902, p. 140)

\section{Predicados amalgamados}

¿Es posible, entonces, mediante el aparato de la lógica de primer orden, proporcionar una formalización de (1) que represente adecuadamente sus condiciones de verdad, y su papel en las correspondientes inferencias?

Efectivamente, sí hay para ello una vía disponible. Y dicha vía consiste sencillamente en la introducción de una nueva letra predicativa, digamos $S$, también con el significado "regir los destinos de", pero esta vez que sea ternaria, y con la particularidad de que reserve sus dos primeros lugares argumentales para los términos correspondientes a los regidores, y el tercero, para el término correspondiente al país regido. Esto es: de tal modo que $S(x, y, z)$ signifique " $x$ e $y$ rigen los destinos de $z$ ".

Siendo así, bastaría con poner $S(i, f, e)$ por (1), y $\exists w S(i, w, e)$, por ejemplo, por (3), y, efectivamente, la inferencia de una a otra se obtendría de inmediato en el cálculo de predicados de primer orden, o en cualquier otro sistema deductivo equivalente.

De hecho, ese tipo de procedimiento es precisamente la estrategia acostumbrada en lógica de primer orden cuando tenemos que enfrentarnos a casos de predicación colectiva como (1). Ahora bien, cabe preguntarse: ¿se trata de una estrategia totalmente satisfactoria? La respuesta, en mi opinión, es nuevamente "no", porque esa forma de notación nos obliga en definitiva a introducir dos letras predicativas distintas $(R$ y $S$ ) para formalizar un mismo predicado ("regir los destinos de") que se utiliza con el mismo significado en ambos enunciados.

Además, si ese mismo predicado, en otro enunciado distinto, se aplicara a un sujeto plural de tres o cuatro personas, necesitaríamos introducir nuevas letras predicativas para representarlo, de manera 
que, para formalizar un único predicado, se daría lugar a una amalgama de letras predicativas distintas, cada una correspondiente a la estructura de la colectividad a que se aplicara en cada caso.

Con esto quiero decir que, aunque la pura lógica de primer orden es, sin duda, una herramienta suficiente para representar formalmente la inferencia de (1) a (3), y garantiza, por tanto, su validez como inferencia puramente lógica, no constituye una herramienta de formalización enteramente satisfactoria. Y la razón por la cual no es enteramente satisfactoria es que nos obliga a introducir una amalgama de letras predicativas distintas para representar lo que esencialmente constituye un único predicado. Es, por consiguiente, esa distorsión en el paso de formalización lo que se cuestiona aquí.

También hay que tener en cuenta que el modo de formalización en lógica de primer orden que estamos comentando no sólo encubre la identidad de significado entre $R$ y $S$, sino que encubre asimismo el paralelismo entre la función que realiza $c$ en el enunciado $R(c, e)$ y la función que realizan $i$ y $f$, conjuntamente considerados, en el enunciado $S(i, f, e)$. Y encubre, en definitiva, el vivo contraste existente entre la forma lógica respectiva de los enunciados (1) y (2).

Debemos insistir, en cualquier caso, en el hecho de que la inferencia de (1) a (3) se pueda representar como una inferencia válida en la lógica de primer orden, a pesar de que la formalización necesaria para ello resulte un tanto sui generis. Este hecho demuestra, en algún sentido fundamental, que dicha inferencia es una inferencia puramente lógica, con todo lo que ello conlleva.

\section{Predicados poligraduados}

A diferencia de los predicados habitualmente admitidos en la lógica de primer orden clásica, que son predicados "de grado fijo", los predicados poligraduados (multigrade predicates) son predicados que poseen un grado o número de lugares argumentales variable. Es decir, son predicados cuyo número de lugares argumentales puede cambiar dentro de unos límites determinados.

El uso de predicados poligraduados nos proporciona una manera distinta de formalizar (1); a saber, mediante una letra predicativa, digamos $T$, que admita un número variable de términos para los regidores, y que tenga, separadamente, un lugar argumental fijo para ocuparlo con el término correspondiente al país regido.

Recientemente, Oliver y Smiley han introducido una terminología muy a propósito para describir $T$ : como una letra predicativa de dos "lugares", pero con un número variable de "posiciones" en el primer 
lugar (Oliver y Smiley 2004, pp. 615-618). Es decir, la letra predicativa $T$ tendría un primer lugar, el correspondiente a los regidores, que podría estar ocupado por un número variable de términos, cada uno de ellos ocupando una posición de ese primer lugar. Y tendría un segundo lugar, el correspondiente al país regido, que es de posición única, y que por consiguiente debe ser ocupado por un solo término.

De este modo, adoptando la sintaxis de los predicados poligraduados, tanto $T(c, e)$ y $T(l, e)$, como $T((i, f)$, e), serían fórmulas aceptables. Ello nos permitiría, por fin, ofrecer una representación transparente del contraste entre las formas lógicas de (1) y (2):

$$
T(c, e) \wedge T(l, e) \quad T((i, f), e)
$$

Hay que hacer notar que probablemente Oliver y Smiley no aceptarían ese modo de análisis de las diferencias entre (1) y (2) por razones que explicaremos más adelante. Pero antes de ocuparnos de eso tenemos que tratar un problema más inmediato.

\section{Predicaciones sobre colectividades complejas}

La subdivisión en lugares y posiciones de Oliver y Smiley se enlaza con una distinción habitual en la literatura sobre predicados poligraduados, desde Leonard y Goodman 1940 (p. 53), pasando por Morton 1975 (pp. 309-310), Mundy 1989 (pp. 126-127) o Taylor y Hazen 1992 (p. 376). Lo que resulta curioso, sin embargo, es que ninguno de estos autores se haya planteado la necesidad de describir predicados poligraduados de estructura más compleja.

$\mathrm{Y}$ el caso es que resulta sencillo encontrar ejemplos de predicaciones colectivas un poco más sofisticadas, para las cuales la subdivisión en lugares y posiciones se vuelve insuficiente.

Pensemos, por ejemplo, en el tándem que formaban Isabel la Católica y el cardenal Cisneros. Un tándem que nos puede llevar a afirmar, quizá exagerando un poco:

(4) "Isabel junto con el cardenal Cisneros, y el rey Fernando, rigieron los destinos de España"

Pues bien: ocurre que, en el enunciado (4), la expresión "Isabel junto con el cardenal Cisneros" parece ocupar exactamente el mismo sitio y función que la expresión "Isabel" a secas ocupaba en (1). Sin embargo, la letra predicativa poligraduada $T$ resulta ahora insuficiente para formalizar (4), ya que tendría que admitir una ulterior subdivisión de dos argumentos distintos, dentro de la primera posición de su primer lugar argumental. 
En otras palabras: la letra predicativa poligraduada $T$ se muestra inadecuada para formalizar (4) porque, aunque admite una multiplicidad variable de regidores, no admite que uno de esos regidores esté a su vez constituido por una multiplicidad de individuos distintos. Además, resulta evidente la analogía entre el tipo de inadecuación de la letra poligraduada $T$ para formalizar (4), y el tipo de inadecuación que tenía la letra predicativa de grado fijo $R$ para formalizar (1), por la cual empezamos el presente artículo.

Sería un error, por consiguiente, intentar remediar esta situación mediante una ampliación de la taxonomía de lugares y posiciones, en la cual se introdujese una tercera subdivisión de casillas argumentales dentro de cada posición. Todo lo que vaya por el camino de describir muy pormenorizadamente las posibilidades argumentales de cada predicado estará siempre expuesto a ejemplos más sofisticados que no encajen en la estructura descrita. Es por ello que la vía adecuada para tratar los casos como (4) ha de ser otra.

\section{Términos compuestos}

Parece mucho más oportuno, precisamente, tratar este tipo de casos partiendo de una estrategia bien distinta; a saber, permitiendo que los lugares argumentales de un predicado puedan ser ocupados por lo que podríamos llamar "términos compuestos", además de por los términos individuales habituales. Esto es: por términos consistentes en una composición de términos individuales, que, funcionando en bloque, puedan aparecer en un determinado enunciado ocupando un solo lugar argumental del predicado que les corresponde.

¿De qué manera podríamos dar una definición de término que incluyera tanto los términos individuales habituales, como estos nuevos términos compuestos que estoy proponiendo aquí? Muy sencillo. Bastará con estipular, en primer lugar, que los términos individuales son las variables y las constantes, como de ordinario (omitamos, para simplificar, los términos funcionales y los descriptores). En segundo lugar, especificamos que cualquier término individual constituye un término. Y a continuación estipulamos (cláusula recursiva) que cualquier fila de dos o más términos, separados por comas y delimitada la fila entera por un par de paréntesis exteriores, constituye a su vez un nuevo término. ${ }^{1}$

Los términos resultantes de aplicar la cláusula recursiva que acabamos de citar los denominaremos "términos compuestos". Por con-

\footnotetext{
${ }^{1}$ Esto es: si $t_{1}, \ldots, t_{n}$ son términos (para $n \geq 2$ ), entonces $\left(t_{1}, \ldots, t_{n}\right)$ es también un término.
} 
siguiente, un término compuesto de nuestro lenguaje será cualquier término que no sea un término individual. La recursividad de la citada cláusula garantiza que cualquier término compuesto ya formado pueda ser utilizado como elemento de otra combinación de términos para dar lugar a un término compuesto de longitud mayor. Esto nos permite, evidentemente, formar términos compuestos tan largos y complejos como queramos.

\section{La distribución interna de los términos compuestos}

La utilización de términos compuestos nos permite llevar a cabo un nuevo análisis de la forma lógica del enunciado (4) que quizá resulte especialmente esclarecedor.

En efecto, podríamos decir que el predicado "regir los destinos de" aparece allí combinado con un término compuesto; a saber: "Isabel junto con el cardenal Cisneros, y el rey Fernando". Dicho término habría de ser analizado a su vez como la combinación de una pareja de términos distintos, que serían los siguientes: en primer lugar, el término "Isabel junto con el cardenal Cisneros" (esto es, "Isabel y el cardenal Cisneros"), que a la sazón resultaría ser él mismo una composición de términos individuales (el término "Isabel" y el término "el cardenal Cisneros"); y, en segundo lugar, el término individual "el rey Fernando", tal cual.

Claro está que la distribución interna del término "Isabel junto con el cardenal Cisneros, y el rey Fernando", que estamos inspeccionando, resulta esencial para determinar las condiciones de verdad del enunciado (4), y de cualquier otro enunciado en que dicho término aparezca; ya que no sería verdadero, por ejemplo, afirmar que "El rey Fernando junto con el cardenal Cisneros, e Isabel, rigieron los destinos de España".

Pues bien, admitiendo todo esto, es decir, admitiendo la utilización de términos compuestos para la formalización, tal y como la estoy proponiendo, entonces resulta posible por fin (ahora sí) dar una representación uniforme de (1), (2), (3) y (4). En efecto, tomando la misma letra predicativa binaria $R$ con la que empezamos, y poniendo ahora, por ejemplo, $n$ por "el cardenal Cisneros", la formalización de estos cuatro enunciados quedaría transparentemente consignada mediante las cuatro fórmulas siguientes:

$$
R((i, f), e) \quad R(c, e) \wedge R(l, e) \quad \exists x R((i, x), e) \quad R(((i, n), f), e)
$$


Y por el mismo procedimiento, resulta evidente, será posible representar también cualquier otro caso de predicación colectiva al estilo de (4), por muy complicada que sea.

\section{Lógica de primer orden con términos compuestos}

Aunque pueda parecer sorprendente, la utilización de términos compuestos, tal y como yo los he definido aquí, apenas exige variaciones con respecto al tratamiento usual de la lógica de primer orden clásica. Tanto es así, que podríamos decir que lo que se obtiene mediante la incorporación de este nuevo tipo de términos es meramente una variante de la lógica de primer orden clásica en su presentación habitual. Veámoslo.

En efecto, una vez que admitimos que un término cualquiera $t$ de nuestro lenguaje formal pueda ser, o bien un término individual, o bien un término compuesto, resulta que no hay que modificar en absoluto la definición ordinaria de fórmula, ni en particular la de fórmula atómica, para acomodar este nuevo tipo de términos.

Basta decir, por ejemplo, que dada una letra predicativa $n$-aria $F$, y cualesquiera $n$ términos $t_{1}, \ldots, t_{n}$, la expresión $F\left(t_{1}, \ldots, t_{n}\right)$ constituirá una fórmula (atómica). En dicha fórmula, los argumentos de la letra predicativa $F$ serán cada uno de los términos $t_{1}, \ldots, t_{n}$, y ello ocurrirá independientemente de que cada uno de ellos sea un término individual o compuesto. $\mathrm{Y}$ en cuanto al resto de la definición de fórmula, puede permanecer sin variación ninguna respecto de las presentaciones habituales.

Por lo que toca a la semántica del lenguaje formal resultante, tampoco hay, frente a lo que podría parecer, grandes diferencias. En efecto, tomemos una interpretación $I$ adecuada al lenguaje formal, y supongamos, para simplificar, que $I$ incorpora también directamente una asignación de valores a las variables del lenguaje (esto es, I consiste en una interpretación suplementada con una asignación de valores a las variables).

Entonces, estipularemos que $I$ debe asignar a cada término individual (constante o variable) un objeto de su universo, tal y como se hace habitualmente. Y una vez hecho esto, añadiremos la estipulación adicional de que $I$ asigne a cada término compuesto del lenguaje una secuencia ordenada de objetos, de la manera que se indica a continuación. Esta secuencia estará construida a partir de la previa asignación de objetos a los términos individuales que compongan ese término.

En efecto, para llevar a cabo dicha asignación, lo primero que tenemos que hacer es definir formalmente el concepto de una secuencia 
ordenada de objetos $\left\langle a_{1}, \ldots, a_{n}\right\rangle$ como una función $f:\{1, \ldots, n\}$ $\longrightarrow\left\{a_{1}, \ldots, a_{n}\right\}$ tal que $f(i)=a_{i}$ (para todo $\left.i, 1 \leq i \leq n\right) .^{2}$

A continuación definiremos el concepto de entidad $n$-aria de $I$, estipulando que cualquier objeto del universo de $I$ es una entidad monaria de $I$, y que si $a_{1}, \ldots, a_{n}$ son entidades de $I$, entonces la secuencia $\left\langle a_{1}, \ldots, a_{n}\right\rangle$ es una entidad $n$-aria de $I$ (cláusula recursiva). En otras palabras: las entidades de $I$ serán tanto los objetos individuales del universo de $I$, como las secuencias de objetos, y las secuencias de secuencias, etc., que hayan sido formadas a partir de los objetos de $I$.

Una vez hecho esto, podemos pasar ya a especificar el valor que tiene un término cualquiera $t$ bajo la interpretación I. Para ello empleamos una vez más la forma de definición inductiva o recursiva. Así, empezamos por el caso en que $t$ sea un término individual (esto es, una constante o una variable). En ese caso estipulamos que $I$ asigne a $t$ directamente un objeto individual de su universo, como es habitual (recordando que en este caso hemos exigido que $I$ incorpore también una asignación de valores a todas las variables del lenguaje).

A continuación suponemos que $t$ sea un término compuesto $n$-ario $\left(t_{1}, \ldots, t_{n}\right)$. Entonces, por hipótesis de inducción, podemos presumir que ya conocemos los valores que $I$ asigna a cada uno de los términos componentes $t_{1}, \ldots, t_{n}$; esto es, podemos presumir que ya conocemos los valores $t_{1}^{I}, \ldots, t_{n}^{I}$. Y, en tal caso, estipulamos que el valor que la interpretación $I$ asigne a $t$ sea precisamente la correspondiente secuencia ordenada $\left\langle t_{1}^{I}, \ldots, t_{n}^{I}\right\rangle$.

Por último, estipularemos que a cada letra predicativa $n$-aria $F$, la interpretación $I$ debe asignarle un conjunto de secuencias $n$-arias basadas en el universo de $I$. Y diremos que la interpretación $I$ satisface una fórmula atómica $F\left(t_{1}, \ldots, t_{n}\right)$ si y sólo si la secuencia $\left\langle t_{1}^{I}, \ldots, t_{n}^{I}\right\rangle$ pertenece al conjunto de secuencias que $I$ asigna a $F .^{3}$

\footnotetext{
${ }^{2}$ La otra definición habitual de secuencia, de acuerdo con la cual, por ejemplo, tenemos que $\langle a, b, c\rangle=\langle a,\langle b, c\rangle\rangle$, no vale aquí por razones obvias: necesitamos distinguir, por ejemplo, entre la tríada $\langle a, b, c\rangle$, cuyos componentes son los objetos $a, b$ y $c$ tomados directamente, y el par ordenado $\langle a,\langle b, c\rangle\rangle$, cuyos componentes son el objeto $a$, y el par ordenado $\langle b, c\rangle$. Tales distinciones pueden tener influencia en el valor de verdad de los enunciados respectivos, como acabamos de señalar en $\S 7$ al hablar de la distribución interna de los términos compuestos.

${ }^{3}$ Estoy preparando, para un próximo trabajo, una descripción minuciosa del formalismo indicado, dentro de un estudio de carácter más general que conectará, además, el fenómeno de la predicación colectiva con otros fenómenos lógicos afines.
} 


\section{Lógicas singulares}

Es muy importante subrayar un aspecto esencial de la definición de término compuesto que estamos manejando aquí: un término compuesto consiste siempre, según la definición que he dado, en una composición de términos individuales (una composición de términos individuales que, funcionando en bloque, se comportan, desde el punto de vista lógico, como un nuevo término). Al formular dicha definición he exigido de forma deliberada que los elementos básicos que conforman un término compuesto hayan de ser siempre necesariamente términos individuales, de tal modo que la unidad básica de la referencia (o denotación) objetual siga siendo el objeto individual; es decir, de tal modo que la unidad básica de la referencia siga siendo estrictamente singular.

Por esa razón, el resultado de añadir a la lógica de primer orden clásica los términos compuestos, siempre que éstos se definan tal y como lo hemos hecho aquí, seguirá constituyendo como sistema lógico una lógica singular, esto es, una lógica basada esencialmente en la consideración del individuo singular.

Por ello mismo, y en plena coherencia con esa idea, el tratamiento de la cuantificación en el sistema que estoy proponiendo habrá de ser exactamente el mismo que en la lógica de primer orden clásica; esto es, de tal modo que sólo se permita la cuantificación sobre variables individuales. Así se consigue que la unidad básica, no sólo de la referencia, sino también de la cuantificación, sea exclusivamente el individuo u objeto singular.

En consecuencia, nuestro sistema permitirá representar de un modo transparente la estructura lógica de un enunciado como (3), por ejemplo, en el que se afirma que "hubo alguien [una sola persona] que, junto con Isabel, rigió los destinos de España". Porque en dicho enunciado se está cuantificando existencialmente sobre un único individuo (aunque la misma cuantificación se utilice inmediatamente después para ligar al individuo cuantificado con un colectivo de otros individuos).

Del mismo modo, el sistema que estoy proponiendo también permitirá, por ejemplo, que se traslade de una manera directa y natural un enunciado como "hubo dos personas que, juntas, rigieron los destinos de España" (esto es: $\exists x \exists y R((x, y), e)$ ), porque en tal enunciado la unidad de cuantificación sigue siendo esencialmente individual.

Pero nuestro sistema no permitirá, en cambio, la representación inmediata de otro tipo de enunciados en los que se efectúe una cuantificación o una referencia directa sobre una pluralidad de objetos sin 
que simultáneamente se encuentren cuantificados o referidos individualmente cada uno de ellos. Veremos algunos casos de este otro tipo de enunciados en seguida.

\section{Vuelta a los objetos compuestos}

La limitación a la que me acabo de referir tiene sus ventajas, como vamos a comprobar inmediatamente, porque es justo la que nos permite mantenernos dentro del ámbito de una mera variante de la lógica de primer orden clásica. La clave de ello reside, vuelvo a decirlo, en que la unidad básica de la referencia y de la cuantificación siga siendo el objeto singular, tal y como ocurre en la lógica de primer orden clásica en su presentación ordinaria.

$\mathrm{Y}$ es que en realidad lo único que estoy proponiendo, se podría decir, es dar una cobertura lógica precisa (la más simple y parca posible) a la idea de "objeto compuesto" barruntada por Frege en sus ejemplos relativos a "Siemens y Halske" y a "Bunsen y Kirchoff" que mencionamos en $\S 2$ (ejemplos ambos, por cierto, construidos a partir de términos individuales, y por lo tanto, ceñidos también a la utilización del objeto singular como unidad básica de la referencia).

Por lo tanto, mi propuesta quiere ser, en definitiva, tan sólo una forma sencilla de proporcionar un formato más propicio para dar una representación transparente y natural de enunciados como (1), (2), (3) y (4), así como de la red de inferencias en la que dichos enunciados están inmersos (por ejemplo, la inferencia que va de (1) a (3)). Un formato más natural que aquella estrategia de predicados amalgamados que describimos en $\S 3$, pero que a la postre venga a ser en el fondo equivalente a ella.

En efecto, tal y como vimos en $\S 3$, la inferencia de (1) a (3) resulta deducible en el cálculo de predicados de primer orden, mediante la estrategia de predicados amalgamados allí descrita. Dicha estrategia hace que la forma de efectuar la inferencia, dentro de la lógica de primer orden al uso, sea algo artificiosa, pero perfectamente válida y legítima desde el punto de vista formal. Y el hecho mismo de que exista esa estrategia demuestra que la inferencia de (1) a (3) es una inferencia lógica "elemental" en el sentido técnico del término; esto es, se trata de una inferencia perteneciente al puro ámbito de la lógica de predicados de primer orden.

Pues bien, el sistema que estoy proponiendo, la lógica de primer orden con términos compuestos, no requiere tampoco ninguna modificación en el sistema deductivo correspondiente. No es necesario incorporar ningún axioma ni regla deductiva adicional para regular 
el comportamiento de los términos compuestos: el sistema deductivo utilizado por la lógica de primer orden con términos compuestos debe ser exactamente el mismo que el que se utiliza en la lógica de primer orden habitual, en cualquiera de sus versiones.

Para ver esto, tomemos por ejemplo los enunciados (1) y (3), formalizados como dijimos en $\S 7$, esto es: $R((i, f), e)$ y $\exists x R((i, x), e))$. Pues bien, para efectuar la deducción formal de uno a otro, bastará utilizar la regla habitual de instanciación existencial aplicada a la constante $f$ que aparece en el término $((i, f), e)$, de un modo similar a como, por ejemplo, se aplica esta regla a las constantes que aparecen en el interior de los términos funcionales. Y no hace falta más.

Por consiguiente, la completud de la lógica de primer orden al uso implica la completud de la lógica de primer orden con términos compuestos, siendo el conjunto de axiomas necesarios para uno y otro sistemas exactamente el mismo. De hecho, cada deducción formal del sistema que propongo, en la que intervengan términos compuestos, tendrá un obvio correlato en la lógica de primer orden al uso, mediante la introducción de letras predicativas de diferentes grados (como la letra predicativa empleada para representar la inferencia de (1) a (3)). De ahí que pueda decir que el sistema que estoy proponiendo es equivalente o es una mera variante de la lógica de primer orden en su presentación habitual.

\section{La lógica plural}

Una vez que han quedado claramente delimitados los términos y el alcance de mi propuesta, ha llegado el momento de compararla con otra iniciativa teórica de carácter mucho más general, de la cual debe ser cuidadosamente diferenciada. Me refiero a la llamada "lógica plural" (o "lógica de la cuantificación plural").

La lógica plural es aquella extensión de la lógica de primer orden clásica en la cual se admite que un término no compuesto refiera directamente a una pluralidad de individuos, y que se pueda cuantificar asimismo sobre "pluralidades" de individuos del universo de discurso. La lógica plural admite representar de una manera directa y natural enunciados en los que se refiere o se cuantifica directamente sobre una pluralidad de individuos, sin pasar por una referencia o cuantificación individual de cada uno de los miembros de la pluralidad en cuestión.

Ejemplos de este otro tipo de enunciados son, verbigracia, "Hubo unas personas que juntas rigieron los destinos de España", o "Los puntos que están en un mismo plano y a la misma distancia de 
un punto dado forman una circunferencia". 4 En estos dos enunciados, como vemos, se cuantifica directamente sobre las pluralidades en cuestión sin pasar por una cuantificación individualizada de sus componentes, y se efectúa una predicación que sólo se aplica colectivamente a la pluralidad sobre la que se cuantifica.

Se trata, por lo tanto, de enunciados que poseen una marcada diferencia lógica con respecto a los enunciados vistos hasta ahora, como se demuestra por el hecho de que, para su formalización y tratamiento lógico, exigen utilizar una teoría mucho más fuerte que la simple lógica de primer orden clásica (ya sea la teoría de conjuntos, la lógica de segundo orden, la propia lógica plural, o algún otro sistema al efecto).

La lógica plural es un sistema inspirado en Morton 1975 y Boolos 1984, y desarrollado en Rayo 2002, Linnebo 2004 y Burgess 2004, entre otros. Este sistema de lógica incorpora términos especiales para denotar pluralidades ("constantes plurales" y "variables plurales"), admite la cuantificación directa sobre esas variables plurales y requiere la introducción de un nuevo operador lógico para representar el hecho de que un individuo pertenezca a una determinada pluralidad (el operador among, como lo denomina, por ejemplo, Burgess 2004, p. 197). La lógica plural tiene, por consiguiente, un alcance mucho más amplio que la mera la lógica de primer orden (y ello es así, evidentemente, tanto si incluimos en la lógica de primer orden los términos compuestos, como si no lo hacemos).

En contrapartida, sin embargo, se ha establecido que la lógica plural no es recursivamente axiomatizable ( $c f r$. otra vez Burgess 2004, p. 220), como tampoco lo son ni la teoría de conjuntos ni la lógica de segundo orden, como es bien sabido. La lógica plural constituye, por tanto, un sistema de lógica no clásica, y más concretamente, una extensión de la lógica de primer orden clásica.

Por consiguiente, aunque la lógica plural también puede dar cuenta, desde luego, de la inferencia de (1) a (3), lo hace mediante la utilización de patrones formales que van mucho más allá de la pura lógica de primer orden. $\mathrm{Y}$ en este sentido, constituye una estrategia comparable, al menos en una primera aproximación, a la utilización de la teoría de conjuntos para dar cuenta de esa misma inferencia que ya comentamos en su momento. ${ }^{5}$ De ahí que yo defienda la

${ }^{4}$ Agradezco estos dos ejemplos a uno de los evaluadores designados por Crítica para la revisión de este artículo.

${ }^{5}$ Sobre la afinidad, las diferencias e interconexiones mutuas entre la lógica plural y la teoría de conjuntos, puede consultarse también Burgess 2004, que está enteramente dedicado a ellas. 
utilización de un sistema más parco y sencillo para casos como (1), (2), (3) y (4), en los que realmente no se necesita apelar a instancias más fuertes. ${ }^{6}$

\section{Predicados colectivos, distributivos y mixtos}

Así pues, mi primera conclusión en el presente artículo es que, para representar adecuadamente la estructura lógica de los enunciados de predicación colectiva sin salirse del ámbito de la lógica de primer orden, hay que admitir que los lugares argumentales de un predicado pueden estar ocupados por términos compuestos, además de por términos individuales. Sólo de ese modo la formalización reflejará de un modo transparente la estructura de la predicación y su profunda desemejanza con la de la predicación distributiva.

Por otra parte, resulta curioso comprobar la falta de consenso en la literatura lógico-lingüística reciente, no sólo sobre el criterio de definición de la distinción colectivo/distributivo, sino incluso sobre el tipo de entidades a las que debe aplicarse.

En efecto, la oposición colectivo/distributivo aparece atribuida a veces a los predicados: Winter 2002, p. 495; Linnebo 2004, § 1.1; Oliver y Smiley 2001, p. 289; 2004, p. 612; otras veces se atribuye a las "lecturas" de una oración: Lasersohn 1995, p. ix; otras más, a las "lecturas" o acepciones de un predicado: Schwarzschild 1996, p. 57; Rayo 2002, p. 439; y otras, en fin, simplemente a los "plurales": Rouilhan 2002, p. 189; o a las "referencias plurales": Cameron 1999, p. 128.

Pero, además, la forma en que se caracteriza la distinción en cada uno de estos lugares varía notablemente de uno a otro. En efecto, si consideramos un par de oraciones como:
(5) " $a$ y $b$ son $P$ "
(6) " $a$ es $P$ y $b$ es $P$ ",

la definición de distributividad exigiría, para Cameron (loc. cit.), que (5) implique (6); para Lasersohn (loc. cit.), que (5) requiera (6); para Rayo (loc. cit.), que (5) se pueda parafrasear mediante (6);

${ }^{6}$ En cualquier caso, el sistema que acabo de describir en las secciones precedentes no debe ser considerado como una propuesta alternativa a la lógica plural, sino más bien como complementaria de ella. De hecho, los términos compuestos definidos aquí podrían ser añadidos a un lenguaje plural, para obtener un sistema interesante por sí mismo. Así, por ejemplo, un término compuesto que consista por entero en términos individuales podría ser reemplazado por una variable plural sin pérdida de gramaticalidad. (Agradezco esta observación a uno de los evaluadores designados por Crítica.) 
para Oliver y Smiley (loc. cit.), que (5) y (6) sean equivalentes; y para Linnebo (loc. cit.), que el bicondicional "(5) si y sólo si (6)" sea una verdad analítica.

Debemos empezar por apuntar, de entrada, el peligro de aplicar esta distinción sin más a un predicado, ya que con frecuencia un mismo predicado (e incluso una misma oración) puede funcionar de las dos maneras.

Es cierto que algunos predicados sólo admiten una utilización distributiva: aquellos que no se pueden aplicar a una colectividad de sujetos sin que el predicado recaiga inmediatamente sobre cada uno de sus miembros; como "estar durmiendo", "coger la gripe", "beber agua", etc. (típicamente, los relacionados con funciones vitales). Así, resulta imposible, por ejemplo, que "Isabel y Fernando están durmiendo" sea un enunciado verdadero sin que sean verdaderos también los enunciados "Isabel está durmiendo" y "Fernando está durmiendo".

$\mathrm{Y}$ es cierto que hay otros predicados que sólo admiten una utilización colectiva: aquellos que nunca permiten la distribución entre los sujetos de la colectividad a que se aplican; por ejemplo "ser una pareja feliz", "formar un excelente cuarteto", "encontrarse en el bar", etc. Así, de "Isabel y Fernando son una pareja feliz" no puede inferirse en ningún caso "Isabel es una pareja feliz" o "Fernando es una pareja feliz", dado que estos enunciados no tienen sentido por separado.

Pues bien, a esos dos grupos de predicados se debe añadir inexcusablemente un tercero, de predicados "mixtos", los cuales, como bien señala Winter (2002, p. 495), son ambivalentes entre los dos usos anteriores; es decir, un grupo de predicados que permiten los dos usos, el colectivo y el distributivo. A este grupo de predicados mixtos pertenece, desde luego, nuestro predicado "regir los destinos de", pero también otros muchos, como "escribir un libro", "izar la bandera", "cantar una canción", "hacer la cena", etc. Así, "Juan y David han escrito un libro" puede significar que han escrito (conjuntamente) un único libro, o bien que cada uno de ellos ha escrito un libro por separado. Y lo mismo con "izar la bandera", "cantar una canción", etcétera.

\section{Predicaciones combinadas}

Sin embargo, sorprendentemente, Oliver y Smiley defienden que el tratamiento lógico de los términos en los casos de predicación colectiva debe ser el mismo que el de los casos de predicación distributiva. 
Esto es, que la diferencia reside únicamente en el tipo de predicado empleado en cada caso (cfr. Oliver y Smiley 2001, pp. 293-295; 2004, pp. 612-614).

El principal argumento de Oliver y Smiley se basa en las predicaciones combinadas, esto es, en aquellos enunciados en los que a un mismo sujeto se le aplican los dos tipos de predicación. Y el argumento en cuestión es que, en tales casos, no se suele detectar ningún indicio de "doble funcionalidad" en la expresión correspondiente al sujeto plural del que se trate:

"Tim y Alex se encontraron en el bar y se tomaron una cerveza" debería provocar un gesto de extrañeza o una sonrisa si el término plural, al ser combinado con "se encontraron en el bar" (colectivo), funcionara de forma diferente de como lo hace al ser combinado con "se tomaron una cerveza" (distributivo), del mismo modo que sonreímos ante "se fue derecho a casa en un mar de lágrimas y una silla de manos". (Oliver y Smiley 2001, p. 294) ${ }^{7}$

Apoyándose principalmente en este argumento, Oliver y Smiley defienden su idea de que la oposición colectivo/distributivo es una característica de los predicados, y no de la forma lógica del enunciado en cuestión. Esto es, que hay predicados colectivos y predicados distributivos, y que ésa es la razón de que un mismo sujeto plural (como "Tim y Alex") pueda ser combinado concatenadamente con distintos predicados de uno y otro tipo ("se encontraron en el bar y se tomaron una cerveza") sin que aparezcan indicios lingüísticos de que dicho sujeto esté desempeñando papeles distintos en su forma de conexión lógica con cada uno de los predicados en cuestión.

Sin embargo, si aceptásemos la propuesta de Oliver y Smiley, y diésemos efectivamente un mismo tratamiento lógico a los dos modos de predicación, entonces ¿cómo habríamos de representar la diferencia de significado que existe, por ejemplo, entre (1) y (2)?

O, por poner un caso más gráfico, consideremos una oración similar a (1) y (2), pero con protagonistas menos conocidos:

\section{(7) "Caserres y Obnelobio rigieron los destinos de Los Grágidos"}

\footnotetext{
${ }^{7}$ La última frase es una cita de The Pickwick Papers (Dickens 1986, cap. 35). El ejemplo del bar y la cerveza procede de Lasersohn 1995 (pp. 96-98), quien a su vez reelabora otros de Dowty 1987 y Roberts 1990. Una formulación independiente del mismo argumento puede encontrarse en Cameron 1999, p. 130.
} 
La oración (7) resultará manifiestamente ambigua, entre la interpretación colectiva y la interpretación distributiva, a todo aquel que no esté familiarizado con los personajes y el lugar en cuestión (es decir, a quien no haya leído El testimonio de Yarfoz (Sánchez Ferlosio 1986, cap. 20). Y, dado que una y otra interpretación tienen diferentes condiciones de verdad y diferentes consecuencias lógicas, resulta imprescindible disponer de una herramienta de formalización que distinga entre ambas.

\section{Predicados amalgamados otra vez}

Se podría proponer, para salvar este escollo, la introducción de dos letras predicativas distintas para formalizar "regir los destinos de": una que representara su utilización para la predicación colectiva y otra que representara su utilización para la predicación distributiva. $\mathrm{Y}$ tal parece ser, en efecto, la idea de Oliver y Smiley, cuando dicen: "nuestro ejemplo 'hicieron la cena' ilustra un rasgo muy extendido; a saber, que con frecuencia una misma expresión se puede leer como un predicado colectivo - la lectura que hemos asumido nosotros-o como uno distributivo" (Oliver y Smiley 2004, p. 612).

Por lo tanto, siguiendo esa propuesta, en (1) y (2) tendríamos en realidad dos predicados distintos: el predicado que aparece en (1) sería el predicado "regir los destinos de" con sentido colectivo (o si se quiere, el predicado "regir los destinos de"-colectivo), mientras que el predicado que aparece en (2) sería el predicado "regir los destinos de" con sentido distributivo (o si se quiere, el predicado "regir los destinos de"-distributivo).

Y el hecho de que el enunciado (2), "Carlos I y Felipe II rigieron los destinos de España" sea equivalente a la conjunción "Carlos I rigió los destinos de España y Felipe II rigió los destinos de España", se consideraría, según esta propuesta, como una mera consecuencia semántica del significado del predicado en cuestión. Esto es, se consideraría una mera consecuencia semántica del significado del predicado "regir los destinos de"-distributivo. Por eso, como apunté en su momento, Oliver y Smiley muy probablemente disentirían del modo de análisis de (1) y (2) propuesto en el presente trabajo, en las secciones 4 y 7 .

Pero mediante tal maniobra estaríamos cayendo, a mi juicio, precisamente en el mismo tipo de error que criticábamos al principio; esto es, el error de formalizar mediante dos letras predicativas distintas lo que esencialmente es uno y el mismo significado. Puesto en otras 
palabras: el error de representar mediante varios predicados distintos lo que esencialmente es un predicado único, porque, desde mi punto de vista, "regir los destinos de" significa lo mismo, tanto si se aplica colectivamente a una pluralidad de individuos, como si se aplica de forma particularizada a uno solo.

Además, podemos comprobar curiosamente cómo el mismo argumento de Oliver y Smiley se vuelve en contra de su propia estrategia (esto es, en contra de la estrategia consistente en desmembrar cada uno de los predicados que aquí hemos llamado "mixtos", como "regir los destinos de", en dos predicados distintos, uno colectivo y otro distributivo).

En efecto, si invertimos las condiciones del ejemplo utilizado por estos autores, podemos constatar que en aquellos otros casos de predicaciones combinadas en las cuales lo que ocurre es que un mismo predicado se utiliza simultáneamente con los dos sentidos (colectivo y distributivo), tampoco se detectan signos de "doble funcionalidad" en la expresión correspondiente a dicho predicado. Y sí deberían detectarse esos signos, siendo coherentes con el planteamiento de Oliver y Smiley, si el predicado en cuestión estuviera funcionando efectivamente de manera ambigua.

Por ejemplo, supongamos que en verdad la expresión "regir los destinos de España" correspondiera a dos predicados distintos, uno para el uso colectivo y otro para el distributivo. Pues bien, siendo así (y siguiendo, como digo, el mismo tipo de argumento propuesto por Oliver y Smiley), un enunciado como "Isabel y Fernando, Carlos I, y Felipe II, rigieron los destinos de España" debería provocar un gesto de extrañeza o una sonrisa, dado que el predicado "rigieron los destinos de España", al ser combinado con "Isabel y Fernando" (colectivo), funciona de forma diferente de como lo hace al ser combinado con "Carlos I y Felipe II" (distributivo). Es decir, el citado enunciado debería producir una sonrisa si el predicado "regir los destinos de" estuviera en efecto ejerciendo una "doble funcionalidad". Pero lo cierto es que tal enunciado resulta tener tan poco efecto hilarante como el ejemplo del bar y la cerveza empleado por Oliver y Smiley.

Por otra parte, ya Cameron (1999, pp. 145-146) había propuesto utilizar un subíndice especial en la formalización, con el fin de marcar de modo visible aquellas ocurrencias de un predicado en las cuales éste se emplease para efectuar una predicación distributiva; de tal forma que los predicados mixtos fueran representados mediante una única letra predicativa, pero acompañada del 
"subíndice de distributividad" en cada ocasión en que se hiciese un uso distributivo de la misma. Esta notación se complementaría con el añadido de una regla adicional al sistema deductivo que permitiera llevar a cabo, en presencia del subíndice de distributividad, las correspondientes inferencias. Pero, a mi entender, no queda claro en absoluto que esta forma de notación sugerida por Cameron sea más ventajosa que la habitual conjunción de oraciones.

En mi opinión, la conclusión que hay que sacar de aquí es precisamente que la existencia de predicados mixtos hace inviable un análisis lógico que trate uniformemente el caso colectivo y el caso distributivo. Y que lo que sugiere esa existencia (y sobreabundancia) de predicados mixtos es que la diferencia de significado de la que nos estamos ocupando no radica en el repertorio de predicados utilizados, sino más bien en la propia estructura de la predicación.

\section{Una oración ambigua doblemente verdadera}

Vamos a examinar a continuación un curioso ejemplo de oración ambigua entre los dos modos de predicación, y que es tal que, en un determinado contexto, resultan ser ambos verdaderos, aun conservando su diferencia de significado; además se da la circunstancia de que, en este caso, el contenido de la predicación distributiva resulta ser deducible del contenido de la predicación colectiva, aunque no como una consecuencia lógica suya, sino como una consecuencia meramente fáctica dadas las circunstancias del caso.

Sucede que la Marquesa de Parabere va a dar un baile de gala y cursa las invitaciones correspondientes por parejas, aunque también admite que los miembros de una pareja invitada asistan independientemente. En estas condiciones, en casa del matrimonio Atienza se recibe una tarjeta que dice:

(8) "El Sr. Atienza y Sra. están invitados al baile"

Si ponemos $a_{1}$ por "el Sr. Atienza", $a_{2}$ por "la Sra. Atienza", $b$ por "el baile" e $I$ por "estar invitado a", parece claro que la estructura lógica del enunciado que hace la marquesa mediante (8) es: $I\left(\left(a_{1}\right.\right.$, $\left.\left.a_{2}\right), b\right)$.

Ahora bien, dadas las normas de la fiesta y estando invitados los dos miembros del matrimonio Atienza, cada uno podrá asistir por separado si así lo desea. Por consiguiente, teniendo en cuenta tales normas, a partir de (8) podemos inferir también: 
(9) “El Sr. Atienza está invitado al baile, y la Sra. Atienza está invitada al baile"

esto es, podemos inferir también: $I\left(a_{1}, b\right) \wedge I\left(a_{2}, b\right)$.

Nótese que, en el presente escenario, la deducción en sentido contrario (de (9) a (8)) no sería posible, ya que de (9) no se sigue necesariamente que el Sr. Atienza y la Sra. Atienza hayan sido invitados como pareja.

Si ahora consideramos una oración ambigua entre esas dos interpretaciones, como

(10) "El Sr. Atienza y la Sra. Atienza están invitados al baile"

tendremos que concluir lo siguiente: $\left(1^{\circ}\right)$ Que la predicación contenida en (10) puede ser entendida de las dos maneras posibles, o bien como una predicación colectiva, o bien como una predicación distributiva. (2 $2^{\circ}$ Que en cada caso se da lugar a un enunciado distinto, aunque en el presente contexto ambos resultan ser efectivamente verdaderos. ( $3^{\circ}$ ) Que el enunciado correspondiente a la lectura distributiva de (10) puede deducirse del otro, pero no como una consecuencia lógica suya, sino como una consecuencia puramente fáctica en virtud de las circunstancias proporcionadas por el contexto.

\section{La estructura de la predicación}

La segunda de las dos tesis principales que trato de defender en este artículo se refiere, en definitiva, a la naturaleza misma de la oposición colectivo/distributivo; cuando menos, a la naturaleza de dicha oposición a efectos del análisis lógico de los enunciados sobre los que sea relevante. Mi tesis es que tal distinción debe considerarse como relativa al modo de ensamblaje o composición lógica del enunciado en cuestión. (Esta posición no es nueva, naturalmente; una idea similar la encontramos, por ejemplo, en Cameron 1999.)

De este modo, la oposición colectivo/distributivo tiene su origen en la forma de conexión entre los (varios) sujetos de la predicación y el predicado (o condición) que dentro de un determinado enunciado se aplica a esos sujetos. Así, la predicación colectiva se produce en cualquier enunciado en el cual un predicado se aplique a una pluralidad de sujetos tomados conjunta o colectivamente. Y la predicación distributiva se produce en cualquier enunciado en el cual un predicado se aplique a una pluralidad de sujetos tomados de forma separada, es decir, tomados de tal forma que el predicado se aplique a cada uno de los sujetos de dicha pluralidad. 
La oposición colectivo/distributivo estriba, por consiguiente, en el modo de distribución del predicado entre los sujetos de la predicación. Y resulta curioso constatar la existencia de casos en los que ambos modos de predicación, siendo distintos, resulten ser simultáneamente verdaderos (como el ejemplo sobre el baile de $\S 15$ ).

La diferencia entre una predicación colectiva y una predicación distributiva no estriba, por tanto, en el tipo de predicado utilizado. Como hemos visto, hay multitud de predicados mixtos, tales como "regir los destinos de", que admiten tanto un uso colectivo como un uso distributivo. Lo que cambia es la estructura lógica del enunciado en cuestión. Por ello, para formalizar un predicado como "regir los destinos de" debemos utilizar una sola letra predicativa del lenguaje formal, tanto para sus usos colectivos como para los distributivos, dejando que sea la estructura de la fórmula la que revele el tipo de predicación (tal y como acontecía, por ejemplo, con la formalización de los enunciados (1) y (2) que propuse en la sección 7).

Por consiguiente, la terminología más apropiada para caracterizar la distinción colectivo/distributivo es la que hemos venido usando desde el principio: "predicación colectiva" frente a "predicación distributiva" (Linnebo 2004, § 1.1, usa ocasionalmente expresiones similares).

Con frecuencia, una misma oración, como (5), (7) o (10), resultará ambigua entre las dos interpretaciones, pudiendo servir para expresar cualquiera de las dos. Pero mientras no sepamos cuál de las dos interpretaciones es la que un hablante concreto ha querido transmitir mediante la oración en cuestión, no podremos decir que hemos entendido correctamente el enunciado que ha hecho.

La ambigüedad en tales casos es estrictamente estructural. Podemos compararla a la ambigüedad a que da lugar una oración de la forma " $\alpha$ y $\beta$ o $\gamma$ " (oración que puede servir para expresar el enunciado " $(\alpha \wedge \beta) \vee \gamma$ " o el enunciado " $\alpha \wedge(\beta \vee \gamma)$ ", dependiendo de la estructura lógica interna que rija la conexión de sus elementos).

Así, en consecuencia, de una oración como (5), entendida en sentido distributivo, cabe decir que requiere (6), que se puede parafrasear mediante (6), o que es equivalente a (6). Pero no es aceptable decir, por ejemplo, que (5) implica (6). Y ello es así exactamente del mismo modo en que no resulta aceptable decir que " $\alpha$ y $\beta$ o $\gamma$ " implica " $(\alpha \wedge \beta) \vee \gamma$ ", o que " $\alpha$ y $\beta$ o $\gamma$ " implica " $\alpha \wedge(\beta \vee \gamma)$ ": la relación de implicación lógica se da, propiamente hablando, entre enunciados distintos, pero no entre una oración y sus posibles interpretaciones (es decir, no entre una oración y los distintos enunciados que se pueden efectuar mediante la proferencia de esa oración). 
Tampoco es correcto afirmar que una oración como (5), entendida en sentido distributivo, es una especie de elipsis gramatical de (6). Así como, por ejemplo, "todo $F$ es $G$ " no es en absoluto una elipsis gramatical de "para todo $x$, si $x$ es $F$, entonces $x$ es $G$ ", aunque este último refleje de manera más transparente la forma lógica del primero (esto es, su papel en la correspondiente red de inferencias). Por eso la casuística lingüística no detectará indicios de elementos elididos en ninguno de esos dos casos (del mismo modo en que, por razones similares, tampoco aparecieron los signos de "doble funcionalidad" en el ejemplo de Oliver y Smiley del bar y la cerveza). Lo que ocurre es, sencillamente, que (6) representa de un modo más transparente y funcional la forma lógica de (5) entendido en sentido distributivo; esto es, que (6) representa de un modo más transparente y funcional sus condiciones de verdad y su papel en la correspondiente red de inferencias. $^{8}$

\section{BIBLIOGRAFÍA}

Aristóteles, 1982, Sobre las refutaciones sofísticas, en Tratados de Lógica (Órganon) I, trad. Miguel Candel, Gredos, Madrid, pp. 309-382.

Boolos, G., 1984, "To Be Is to Be a Value of a Variable (or to Be Some Values of Some Variables)", The Journal of Philosophy, vol. 81, no. 8, pp. 430-449. (Reimpreso en Logic, Logic and Logic, Harvard University Press, Cambridge, Mass., 1998, pp. 54-72.)

Burgess, J.P., 2004, "E Pluribus Unum: Plural Logic and Set Theory", Philosophia Mathematica, vol. 12, no. 3, pp. 193-221.

Cameron, J.R., 1999, "Plural Reference", Ratio (new series), vol. 12, no. 2, pp. 128-147.

Dickens, C., 1986 (1836-1837), The Posthumous Papers of the Pickwick Club, Penguin, Harmondsworth.

Dowty, D., 1987, "Collective Predicates, Distributive Predicates and All", en F. Marshall, A. Miller y Z. Zhang (comps.), Proceedings of the Third Eastern States Conference on Linguistics (ESCOL) '86, Ohio State University, Columbus, pp. 97-115.

Frege, G., 1914, "Logic in Mathematics", Posthumous Writings, Basil Blackwell, Oxford, 1979, pp. 203-250.

—_, 1902, "Letter to Russell: 28.7.1902", Philosophical and Mathematical Correspondence, Basil Blackwell, Oxford, 1980, pp. 139-142.

\footnotetext{
${ }^{8}$ Trabajo financiado por el proyecto FIS2004-01018 del Ministerio de Educación y Ciencia de España. Deseo hacer constar mi agradecimiento a dos evaluadores anónimos de Crítica, por sus valiosos comentarios y sugerencias a varias versiones preliminares de este artículo.
} 
Lasersohn, P., 1995, Plurality, Conjunction and Events, Kluwer, Dordrecht.

Leonard, H.S. y N. Goodman, 1940, "The Calculus of Individuals and Its Uses", Journal of Symbolic Logic, vol. 5, no. 2, pp. 45-55.

Linnebo, O., 2004, "Plural Quantification", en E.N. Zalta (comp.), The Stanford Encyclopedia of Philosophy (Winter 2004 Edition): http://plato.stanford.edu/archives/win2004/entries/plural-quant/

Morton, A., 1975, "Complex Individuals and Multigrade Relations", Noûs, vol. 9, no. 3, pp. 309-318.

Mundy, B. 1989, "Elementary Categorial Logic, Predicates of Variable Degree, and Theory of Quantity", Journal of Philosophical Logic, vol. 18, no. 2, pp. 115-140.

Oliver, A. y T. Smiley, 2004, "Multigrade Predicates", Mind, vol. 113, no. 452 , pp. 609-681.

- 2001, "Strategies for a Logic of Plurals", The Philosophical Quarterly, vol. 51, no. 204, pp. 289-306.

Rayo, A., 2002, "Word and Objects", Noûs, vol. 36, no. 3, pp. 436-464.

Roberts, C., 1990, Modal Subordination, Anaphora and Distributivity, Garland, Nueva York.

Rouilhan, P. de, 2002, "On What There Are", Proceedings of the Aristotelian Society, vol. 102, no. 2, pp. 183-200.

Sánchez Ferlosio, R., 1986, El testimonio de Yarfoz, Alianza, Madrid.

Schwarzschild, R., 1996, Pluralities, Kluwer, Dordrecht.

Taylor, B. y A.P. Hazen, 1992, "Flexibly Structured Predication", Logique et Analyse, vol. 139-140, pp. 375-393.

Winter, Y., 2002, "Atoms and Sets: A Characterization of Semantic Number", Linguistic Inquiry, vol. 33, no. 3, pp. 493-505.

Recibido el 24 de noviembre de 2005; revisado el 31 de marzo de 2006; aceptado el 13 de diciembre de 2006. 